\title{
What Brings Diversified Global Economy into Integration-No. 1 of the Series of Reflections on Economics Law and Ethic Culture Caused by World Financial Crisis
}

\author{
Yu Tian \\ Northwest University of Politics and Law, Xi' an 710063, China \\ E-mail: leihan599@hotmail.com
}

\begin{abstract}
Focused on the macro level of economics law and ethic culture, this paper aims at finding out the fundamental obstacles for sound development of world economy and providing scientific theory for the establishment of a healthy global financial, economic, legal and social system as well as ethic cultural basis.

Through analysis, this paper draws the conclusion that it is modern science and technology that has brought diversified global economy into integration, hence setting a foundation for further theories in this filed.
\end{abstract}

Keywords: World economy integration, Working machine, Modern science and technology

For their mutual benefits, 20 major rich nations and newly emerging nations (G20) are propelling cooperation among each other against the current overwhelming financial crisis. However, its scrape in dealing with some short-term symptoms of world economic crisis by having one after another summit faces us with one question--- "Is this long-lasting disease really curable?". (Wolf et al, 2009)

Since human beings live on material basis, our pursuit for material benefits is natural, just like lions on African grassland prey upon zebras and buffalo. However, what drives us to lose control of our evil profit-earning actions despite visible terrible results? Maybe the following analysis will uncover the veil.

1. Fundamental changes have taken place in people's mode of production and life since the victory of Industrial Revolution in the 18th century and the 19th century.

Industrial Revolution has had not only the epoch-making social significance in the history of human creation of material wealth, but has converted human into a vassal of the working machine.

Due to the superb efficiency of the working machine in creating material wealth, people spare no effort to produce more advanced working machines to create greater wealth in order to obtain all benefits including power brought about by material wealth. Chaplin's classic silent movie Modern Times expresses the relationship between human and the working machine in an exaggerating but truly. Ever since that time, our inflexible desirability for the working machine has grown stronger with its advance in technology. It is even safe to say that modern working machines are totally indispensable in all fields nowadays. If all those were abandoned overnight, we would experience that "the end of the world" had been coming.

Only a 26-hour power failure in New York in 1977 put the whole city into a terrible disorder. In 2003, another overwhelming power failure confined 350,000 people into lifts and tube and nearly 70 fires broke out within over 29 hours after that. This incident caused as serious damage as that caused by 9.11 Terrorist Attack. During the power failure, normal economic life and people's life were drawn to a stop except for some core government departments, Wall Street stock market, hospitals and some important hotels. According to New York Congress, its government suffered from a loss of $\$ 800,000,000$ in its income due to this incident. However, it is estimated by Davi Rosenberg, Chief Economist of Merrill Lynch, that the daily damage caused by it was about $\$ 25,000,000,000$ to $\$ 30,000,000,000$. What would have happened if there had been not any back-up power?

According to American public opinion, this power failure and some mobile phone failures are caused by capitalists' pursuit for profits. It is reported that Consolidated Edison. Inc. has no interest in renewing New York's power grid or investing in new power plants. Along with other companies, it even went to buy cheap hydropower from Niagara Falls in Canada despite the long distance. The same is true of telecommunications companies, who would rather promote new services to obtain profits than spend money in improving their capacity. As a result, American public opinion calls for American Government to enhance its administration on those important industries such as water, power and 
telecommunications by issuing laws and regulations to force relevant companies to put consumers' safety prior to their profits. Despite American Government had given a great efforts, but without enough rigid restrictions between regulations and market discipline, hence failing to prevent such incidents from happening. Instead, another rigid rule of pursuing maximized profits has forced people to give in again and again.

More incidents show that, the dominant status of human beings in the society has been restricted by the modern working machine system deeply, without which human beings will face to horrible results even if not the greatest calamity. It is the internal rigid rule we have to yield to in all situations that has led up to obscureness of the dominant status. Just as working machine was the temptation - fascinated Pandora whom was given by God, we had accepted her, once the box she carried for us was opened, however "all the gifts" flown from her box we also have to suffer, we cannot avoid the results caused by her "gifts".

2. With the archaic morality and culture considered shackles for social development, which were attacked and rebuilded, human beings have established the dominant status of the working machine for selves.

Renaissance, in Western Europe in 16th century, set a basis for new science, technology and culture under color of "restoring classical culture", its real substance is a liberation movement of thinking that world led by science and technology. Subsequently, Enlightenment and Reformation Movements brought about by Renaissance put forward Protestantism, which applied to science and technology society. According to the new concept of Protestantism, Bible is the exclusive foundation and authority for believers to believe in, and people through their faith in Christ have their souls saved, hence overturning the long-lasting Soteriology of salvation through good works and the ultramontanism. As a result of Reformation Movements, the nations was out of the control from the religious theocratic thought, for the future development of science and technology as the core of human rights laid the ideological and cultural foundations.

Two centuries passing by, no matter how admirable the banner of human rights by eastern scorllors held by the western countries is, it has to give way to modern working machines or financial markets in order to fulfill these countries' pursuit for material benefits. The former banner of human rights held high for several centuries had gradually been an accompaniment of the banner of economic benefits since late 20th century.

For a long time, every one in the modern society has to obtain rigid training in social education as well as pattern of thought which began to be constructed under the dominance of the working machine from Industrial Revolution. Therefore, it is the rule and truth of the universe as well as an indispensable part of modern human civilization to make such education system accepted and followed by all global. In such a huge system including the education system ranging from kindergarten to post-doctoral education, a complete set of subject categories and some institutions related to examination, upgrading, elimination, graduation, earning officially-recognized certificates and so on. Trained in the above system, people in the modern society carefully maintain and promote the modern social system of working machines which is guided by advanced technology from obtaining energy resource to using electronic intelligence. Those who deny the dominance of modern working machines will become the enemy against the whole society and those who refuse to receive such education or who don't receive enough education will have no access to modern civilization or be eliminated by the modern society. In a word, with no exception, all changes in traditional culture and morality have to serve the purpose of developing the science system dominated by the modern working machine, human beings work hard in pursuit of maximized profits. This applies to any nation with any kind of ideology, western countries or eastern countries, developed or developing, capitalist or socialist, autocratic monarchy or constitutional monarchy.

3. With agricultural economy and monarchy overturned by market economy and democracy, new economic, political and legal institutions have become the catalyst for the dominance of the working machine over the world and the expansion of human's wish for wealth.

Break away from the Vatican's political and economic control after Enlightenment, a new economic pattern and its corresponding social system, especially the legal protection system of this economic pattern, occurred in Western Europe and then swept the entire world. It is only appearance that all the new systems emphasize on human rights and embody the rationality of human-oriented, in essence, all the systems play this role of disintegrating the dominant status of people in the of the physical world, drive human out of controlling selves to pursue and enjoy material wealth, eventually became a vassal of the modern way of life and wealth, even slaves.

Those developing countries adopting democracy, republic and constitutionalism in Asia, Africa and Latin America, how dictatorship, privilege, or corruption soever, one thing is common to all countries that fully develop modern production and life style in which modern working machine is of dominance, no matter whether they have real democracy or not. Despite the differences in politics between developed countries and developing countries even after their adoption of democracy due to their obvious differences in nations' history, traditional culture, custom, and so on, all of them have similar economic pattern. In other words, the market economy pattern in developed countries is copied by developing countries including China which has one fourth of the world population, and believe in Marxism and socialism in 
ideology. Such a duplication of the production mode will certainly lead to the follow in the mold of life and consumption. Actually, some wealthy people in developing countries even dwarf those world-class billionaires in developed countries in consumption. (2009)

One Masterpiece the Rise of the Western World: A New Economic History. By North and Thomas pours a flood of light on the rising social and legal institutions after Industrial Revolution. that is the reason why economic development and increase rapidly in per capita income first took place in Western Europe after the 18th century since they had more effective economic organization and legal system to protect individual property safety, which a relatively complete economic organization had ran nearly a thousand years since the Middle Ages as the long-term evolution results. Holland and U.K. were particularly outstanding among them since their people had greater capacity to resist against oppression, monopoly and extortion of local powers in politics, religion and city guild forces than those in Spain, France and elsewhere in Europe. As a result, the security of persons and property was safeguarded better there and people had more freedom to operate their enterprises. (1973)

American economists Rosenberg and L.E. Birdzell were famous in the world for their research on technological development history. In their book How the West Grew Rich: The Economic Transformation of the Industrial World, it is proven by conclusive facts that China and Arab countries went ahead of West Europe in science and technology until the 15th century, but it took western countries several hundred years only to surpass eastern economy civilization very much which had been developed for thousands years. A social mechanism which is conducive for continuous innovation was established in Western Europe in the late Middle Ages, which is the important reason. The industrial revolution took place in late 18th century with a lever system as the basis, such a lever system was formed in the late medieval commercial revolution. For example, the double-entry system was invented in the 13th century, a corporation system emerged in the early 17th century, also the modern Civil and Commercial Code issued, untill the final victory of the capitalist democracy system succeeded in the world. It is impossible to win Industrial Revolution without such an institutional protection of economic, political, legal institutions. It is safe to say that the new western economic, political and legal institutions since Middle Ages have strengthened the dominance status of modern working machine over the whole world and intensified the longing of human being for material wealth. Just like what is expounded above, no matter what a country is, any country must obey the powerful modern working machine system. (1987)

\section{Conclusion}

Who has brought about diversified global economy into integration, neither America nor the European Union, but the Pandora whom was presented by Western Industrial Revolution that was born in the late Middle Ages - the working machine, namely, the birth and development of modern science and technology.

\section{Notes}

Note 1. Relevant details can be obtained in the following articles:

Wolf, Martin. (2009). Why did G20 fail to save world economy?. Financial Times. [Online] Available: http://www.ftchinese.com/story/001025575/en (April 1).

Giles, Chris. (2009). A pattern emerges. Financial Times. [Online] Available: http://www.ftchinese.com/story/001028850/en (September 22).

Guha. Krishna (2009). Global challenges have to be tackled. Financial Times. [Online] Available: http://www.ftchinese.com/story/001028831/en (September 21).

Note 2. By breaking the former scholasticism centering on theology, Renaissance prepared ideological liberation for Industrial Revolution. During it, a variety of folk philosophy rose represented by Bacon, Desiderius Erasmus and Machiavelli, hence promoting the development of political theory, setting a foundation for later Enlightenment, encouraging the rise of many thinkers such as Thomas Hobbs, John Locke and Jean-Jacque Rousseau, establishing theories including "natural rights", "social contract", "human rights" and "separation of the three powers" and so on.

Note 3. In order to fight against Former Soviet Union's supremacy, the United States established diplomatic relations with China in 1970s after 30-year antagonism by accepting the requirements given by Chinese Government such as "breaking off its relations with Taiwan" "withdrawing its army" and "annualling former unfair agreements". In the following 30 years, their diplomatic relations were developed to dialogue and cooperation, making their mutual economic interest closely tied. The same is true of the relations between China and the European Union. Despite the impact of the incident of human rights in China, their relations remained healthy due to the dominant role of economic benefits during the course.

Antagonism in ideology is not the nature of the current problem because the opinion of human rights is by nature intended to clear the way for the working machine dominating human beings. Anyone who was against the western opinion of human rights will have his opinion changed once in the social system dominated by the working machine. The only difference between the two sides lies in that one has no democratic constitutionalism to accelerate the 
development of the working machine system. Therefore, some necessary measures need to be taken until such a lever system is completely established. This is explained in detail in the 3 rd part of the paper.

Note 4. More detail can be found in Luxuries Gaining Popularity in China? (http://content.chinasspp.com/News/detail/2009-2-24/71180.htm) published on February 24 $4^{\text {th }}, 2009$.

\section{References}

Douglass C. North. Robert Paul Thomas. (1973). The Rise of the Western World: A New Economic

History Cambridge University Press; 1 edition September 14.

Locke, John. Zhao, Boying (translator). (2005). Two Treatises of Civil Government. Shannxi People's Press. May.

Nathan Rosenberg. L.E. Birdzell Jr. (1987). How the West Grew Rich: The Economic Transformation of the Industrial World Basic Books Press. May 1.

Rousseau, Jean-Jacques. He, Zhaowu (translator). (2003). The Social Contract. The Commercial Press. March. 